\title{
Organ support after death by neurologic criteria
}

\author{
Results of a survey of US neurologists
}

Ariane Lewis, MD

Nellie Adams, BA

Panayiotis Varelas, MD,

$\mathrm{PhD}$

David Greer, MD, MA

Arthur Caplan, PhD

Correspondence to

Dr. Lewis:

ariane.kansas.lewis@gmail.com
Supplemental data at Neurology.org

\section{ABSTRACT}

Objective: We sought to evaluate how neurologists approach situations in which families request prolonged organ support after declaration of death by neurologic criteria (DNC).

Methods: We surveyed 938 members of the American Academy of Neurology (AAN) who treat critically ill patients, including 50\% who practice in states with accommodation exceptions (states that require religious or moral beliefs to be taken into consideration when declaring death or discontinuing organ support: California, Illinois, New Jersey, New York), and 50\% who practice in nonaccommodation states.

Results: The survey was completed by 201/938 individuals (21\% response rate), 96 of whom were from accommodation states and 105 of whom were from nonaccommodation states. Both groups reported encountering situations in which families requested continuation of organ support after DNC (48\% from accommodation states and 46\% from nonaccommodation states). In a hypothetical scenario where a request is made to continue organ support after DNC (outside of organ donation), $48 \%$ of respondents indicated they would continue support due to fear of litigation. In reply to an open-ended question, respondents requested that the AAN generate guidelines and advocate to codify laws regarding organ support after DNC, and to improve public and physician education on DNC.

Conclusions: Our findings suggest that it is relatively common for neurologists who treat critically ill patients to encounter families who object to discontinuation of organ support after DNC at some point during their career. It would be beneficial for physicians, families, and society to rely on clear medicolegal guidelines on management of this situation. Neurology ${ }^{\circledR} 2016 ; 87: 827-834$

\section{GLOSSARY}

AAN = American Academy of Neurology; CPR = cardiopulmonary resuscitation; DNC $=$ death by neurologic criteria.

Death by neurologic criteria (DNC) is legally accepted throughout the United States as equivalent to cardiopulmonary death. ${ }^{1}$ The American Academy of Neurology (AAN) advises that organ support be discontinued after declaration of DNC unless donation is planned, ${ }^{2}$ but families sometimes request continuation of support. ${ }^{3-9}$

Four states have legal accommodation exceptions. ${ }^{10-13} \mathrm{New}$ Jersey's statute states that DNC cannot be declared in violation of a patient's religious beliefs. ${ }^{11}$ In California and New York, hospitals are instructed to make reasonable efforts to accommodate religious or moral objections to DNC. ${ }^{10,12}$ In Illinois, hospitals are told to take religious beliefs into account when determining time of death. ${ }^{13}$

The questions of what constitutes reasonable accommodation and how these situations should be handled in states that do not have accommodation exceptions have left physicians, nurses, administrators, and ethics committees flustered. ${ }^{3,7-9}$

Although there are case reports ${ }^{3-9}$ on management of objection to DNC, there are no universal legal or medical society guidelines to dictate behavior in these challenging cases. As a result, the frequency of objection to DNC and the manner in which individual centers handle

From the Departments of Neurology and Neurosurgery, Division of Neurocritical Care (A.L.), and Department of Population Health, Division of Medical Ethics (A.C.), NYU Langone Medical Center, New York, NY; American Academy of Neurology (N.A.), Minneapolis, MN; Departments of Neurology and Neurosurgery (P.V.), Henry Ford Hospital, Detroit, MI; and Department of Neurology (D.G.), Yale University School of Medicine, New Haven, CT.

Go to Neurology.org for full disclosures. Funding information and disclosures deemed relevant by the authors, if any, are provided at the end of the article. 
Table 1 Personal and institutional characteristics of respondents

\begin{tabular}{|c|c|c|c|}
\hline Characteristics & $\begin{array}{l}\text { Accommodation } \\
\text { state respondents } \\
(\mathrm{n}=96)\end{array}$ & $\begin{array}{l}\text { Nonaccommodation } \\
\text { state respondents } \\
(\mathrm{n}=105)\end{array}$ & $p$ Value \\
\hline Male, $\%^{a}$ & 64 & 64 & 0.96 \\
\hline Age, $y$, mean (SD) & $51(12)$ & $51(11)$ & 0.79 \\
\hline Primary specialty, $\%$ & & & 0.44 \\
\hline General neurology & 69 & 77 & \\
\hline Neurocritical care & 10 & 4 & \\
\hline Neurohospitalist & 3 & 3 & \\
\hline Traumatic brain injury & 1 & 1 & \\
\hline Vascular neurology/stroke & 17 & 15 & \\
\hline Practice setting, $\%$ & & & 0.31 \\
\hline Government hospital/clinic & 7 & 7 & \\
\hline Multispecialty group & 17 & 14 & \\
\hline Neurology group & 11 & 21 & \\
\hline Other public/private hospital/clinic & 6 & 8 & \\
\hline Solo practice & 21 & 20 & \\
\hline $\begin{array}{l}\text { Staff-model health maintenance } \\
\text { organization }\end{array}$ & 5 & 1 & \\
\hline University-based group & 16 & 11 & \\
\hline
\end{tabular}

${ }^{a}$ Data were unavailable for $2 \%$ of accommodation state respondents and $1 \%$ of nonaccommodation state respondents.

these objections is unknown. We sought to better understand this issue by polling neurologists about the way they would handle objections to DNC and their experience with these difficult situations.

METHODS Survey creation. The goals of our survey were to identify (1) how neurologists believe situations in which families request prolonged organ support after declaration of DNC should be handled; (2) resources neurologists use to manage these situations; (3) how frequently these situations arise; and (4) whether there is a need for legislative action or generation of policies or resources by the AAN to help neurologists respond when these situations arise. The survey was reviewed by members of the Critical Care and Emergency Neurology Section; Ethics, Law, and Humanities Committee; and Member Research Subcommittee of the AAN (see appendix e-1 on the Neurology ${ }^{\circledR}$ Web site at Neurology.org). This study was exempt from institutional review board review as responses were de-identified and data review was performed by the AAN.

Survey distribution. To be considered for sample inclusion, members had to (1) be active and out of training; (2) specialize in general neurology, neurohospitalist, neurocritical care, traumatic brain injury, or stroke; and (3) spend at least $25 \%$ of their time in clinical practice.

There were 469 members of the AAN who lived in accommodation states and met criteria for participation. The survey was distributed electronically on September 16, 2015, to these members and to a random sample of 469 of the 1,284 eligible members from nonaccommodation states. After 2 reminder e-mails, the survey was distributed via fax or mail, if fax number was unavailable. Data collection closed on October 30, 2015.
Statistics. To test for differences between groups, responses for accommodation and nonaccommodation state respondents were compared using $\chi^{2}$ or likelihood ratio tests for single-response questions and $t$ tests for each item in mark-all-that-apply questions and for comparison of numerical averages. Analysis was performed with IBM (Armonk, NY) SPSS Statistics version 23 . A $p$ value $<0.05$ was considered to be statistically significant.

RESULTS Respondents. We received responses from 201/938 individuals (21\% response rate), 105 of whom were from nonaccommodation states and 96 of whom were from accommodation states ( 42 from California, 15 from Illinois, 11 from New Jersey, and 28 from New York). Demographic data are reported in table 1. There was no difference in age, sex, or practice setting between respondents and nonrespondents or between accommodation state and nonaccommodation state respondents. There was no difference in primary specialty between accommodation state and nonaccommodation state respondents, but respondents were more likely than nonrespondents to specialize in neurocritical care $(p=0.013)$ or stroke $(p=0.032)$ and less likely to be general neurologists $(p<0.001)$. Five percent of respondents from accommodation states and 1\% from nonaccommodation states reported they did not spend any professional time seeing inpatients in a hospital in the United States and were thus skipped to the end of the survey.

Social and ethical issues. The majority of all respondents $(78 \%)$ strongly or somewhat disagreed that physicians should obtain consent from a patient's family before performing an evaluation for DNC. Opinions about whether permission should be obtained prior to discontinuing organ support for a patient after declaration of DNC varied, with $47 \%$ of respondents strongly or somewhat disagreeing and $42 \%$ strongly or somewhat agreeing ( $11 \%$ were neutral). Views on the need for different policies for objection to DNC in pediatric and adult patients also varied, with $32 \%$ of respondents strongly or somewhat agreeing and $47 \%$ strongly or somewhat disagreeing that policies should be different. Those who agreed indicated via write-in responses that parents need more time to accept the death of a child and that additional ancillary testing should be offered for pediatric patients.

Outside of organ donation and pregnancy, $70 \%$ of respondents believed that there were circumstances in which continuation of organ support should be required after declaration of DNC, while a much larger percentage (95\%) believed that there were circumstances in which physicians should be allowed to continue organ support (see figure 1). There was no difference between responses from accommodation and nonaccommodation states. Table 2 shows the 
Figure 1 The circumstances in which respondents believe a physician should be required/allowed to continue organ support after declaration of death by neurologic criteria

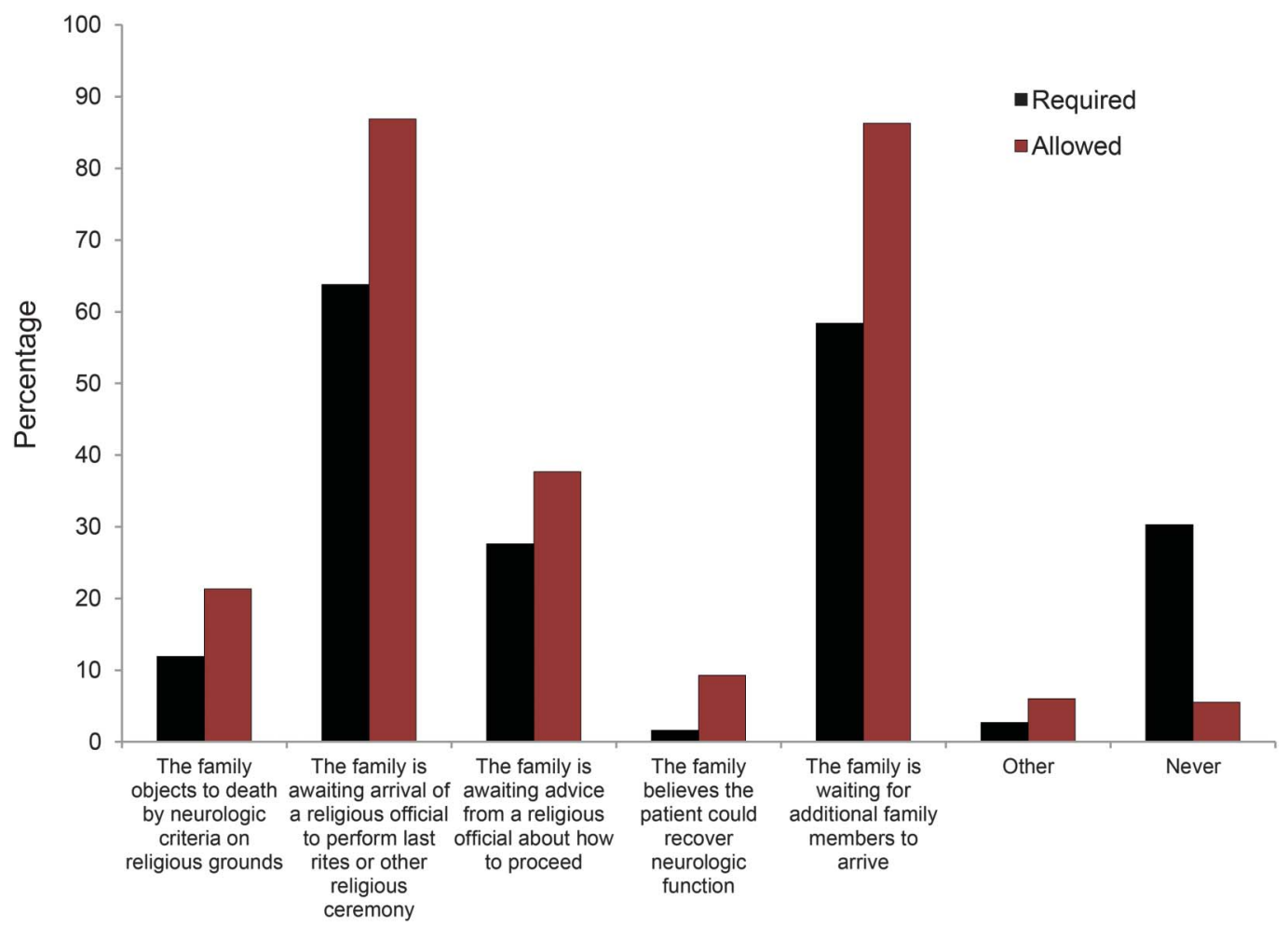

A total of 185 individuals responded to the survey question regarding situations where continuation of organ support should be required. A total of 183 individuals responded to the survey question regarding situations where continuation of organ support should be allowed.

reasons respondents would be willing to accommodate the request of a family who voiced religious objection to DNC and requested continuation of organ support. The most common rationale for continuing organ support after DNC among both groups was the desire to avoid litigation, although a larger proportion of accommodation state respondents selected this response $(57 \%$, vs $41 \%$ of non-law state respondents, $p=0.024)$.

Medical issues. The majority of respondents (86\%) indicated that, outside of organ donation or pregnancy, they would not start any new therapies after declaration of DNC, while $13 \%$ would start IV fluids and $4 \%$ would place a tracheostomy. When asked about continuing therapies that were started prior to declaration of DNC, $60 \%$ of respondents indicated they would be willing to continue at least one of the following: nutrition, IV fluids, hydrocortisone, levothyroxine, vasopressin, antibiotics, or vasopressors (see table 2). In comparison to respondents in nonaccommodation states, those from accommodation states were more willing to continue antibiotics ( $36 \%$ vs $19 \%, p=0.016)$ or vasopressors ( $46 \%$ vs $28 \%, p=0.017$ ) after declaration of DNC. When asked how they would handle code status in a patient who was declared DNC, respondents were divided: more than one-third (39\%) would allow the family to decide if attempts at cardiopulmonary resuscitation (CPR) should be made, while a similar proportion $(34 \%)$ would not perform CPR regardless of family input. Replies did not vary between accommodation state and nonaccommodation state respondents (see table 2).

Legal issues. The majority of respondents (93\%) strongly or somewhat agreed that a person who is DNC is legally dead. Only a small portion of respondents $(16 \%)$ strongly or somewhat agreed that every US state should allow religious or moral objection to DNC. There was no difference between respondents from accommodation and nonaccommodation states for either issue.

Fifty-eight percent of respondents from accommodation states and $83 \%$ of respondents from nonaccommodation states were unaware that any states had accommodation clauses. In fact, the majority of respondents from accommodation states indicated they were unfamiliar with their own state's accommodation exception ( $91 \%$ of respondents from New Jersey, $87 \%$ of respondents from Illinois, $62 \%$ of respondents from California, and 54\% of respondents from New York). 
Table 2 Actions respondents would take if a family voiced religious objection after death by neurologic criteria and requested continuation of organ support (for a patient who is not an organ donor and is not pregnant)

\begin{tabular}{|c|c|c|c|}
\hline & $\begin{array}{l}\text { Accommodation } \\
\text { state respondents }\end{array}$ & $\begin{array}{l}\text { Nonaccommodation } \\
\text { state respondents }\end{array}$ & $p$ Value \\
\hline Reason to continue organ support, ${ }^{a} \%$ & $(n=83)$ & $(n=91)$ & \\
\hline Personal ethical beliefs & 17 & 14 & 0.56 \\
\hline Personal religious beliefs & 5 & 3 & 0.57 \\
\hline Desire to avoid upsetting the family & 41 & 39 & 0.59 \\
\hline Desire to avoid litigation & 57 & 41 & $0.024^{b}$ \\
\hline Desire to avoid media coverage & 33 & 25 & 0.23 \\
\hline Fear of losing job & 10 & 7 & 0.42 \\
\hline Other & 12 & 13 & 0.90 \\
\hline $\begin{array}{l}\text { Never consider accommodating this } \\
\text { request }\end{array}$ & 27 & 26 & 0.86 \\
\hline $\begin{array}{l}\text { Treatments to continue if started prior } \\
\text { to death by neurologic criteria, }{ }^{a} \%\end{array}$ & $(n=69)$ & $(\mathrm{n}=80)$ & \\
\hline Nutrition & 45 & 41 & 0.73 \\
\hline IV fluids & 61 & 48 & 0.18 \\
\hline Hydrocortisone & 23 & 19 & 0.55 \\
\hline Levothyroxine & 25 & 21 & 0.67 \\
\hline Antibiotics & 36 & 19 & $0.016^{b}$ \\
\hline Vasopressors & 46 & 28 & $0.017^{b}$ \\
\hline Vasopressin & 30 & 21 & 0.24 \\
\hline None & 38 & 43 & 0.99 \\
\hline $\begin{array}{l}\text { Treatments to start after death by } \\
\text { neurologic criteria, } \%\end{array}$ & $(n=69)$ & $(\mathrm{n}=80)$ & \\
\hline Nutrition & 7 & 4 & 0.36 \\
\hline IV fluids & 16 & 10 & 0.30 \\
\hline Hydrocortisone & 3 & 5 & 0.51 \\
\hline Levothyroxine & 3 & 4 & 0.76 \\
\hline Tracheostomy placement & 4 & 4 & 0.87 \\
\hline Antibiotics & 4 & 6 & 0.60 \\
\hline Vasopressors & 6 & 4 & 0.57 \\
\hline Vasopressin & 4 & 4 & 0.87 \\
\hline None & 83 & 89 & 0.31 \\
\hline Code status, $\%$ & $(n=63)$ & $(n=69)$ & 0.41 \\
\hline $\begin{array}{l}\text { Issue a do-not-resuscitate order } \\
\text { regardless of family's input }\end{array}$ & 38 & 30 & \\
\hline $\begin{array}{l}\text { Discuss code status with the family } \\
\text { and allow them to decide if attempts } \\
\text { at resuscitation should be made }\end{array}$ & 41 & 38 & \\
\hline Other actions & 16 & 20 & \\
\hline Unsure & 5 & 12 & \\
\hline
\end{tabular}

${ }^{\text {a }}$ Respondents were permitted to select more than one response.

bignificant. believed the family should be responsible, $22 \%$ were unsure, and $2 \%$ thought the hospital should be responsible. For states where accommodation is not legally required, a much lower proportion (10\%) of respondents thought insurance should fund additional hospitalization, while $66 \%$ thought the patient's family should be responsible, $20 \%$ were unsure, $3 \%$ believed charity should pay, and $2 \%$ thought the hospital should be responsible. Responses to either question from respondents in accommodation states and nonaccommodation states did not vary.

Respondents' experience with DNC. Almost all (97\%) respondents reported they had personally declared a patient DNC. Nearly half (47\%) had been asked to continue organ support after declaration of DNC for reasons outside of organ donation $(48 \%$ of respondents from accommodation states and 46\% from nonaccommodation states). In accommodation states, respondents were asked to continue organ support after declaration of DNC a mean of 6.9 times (SD 7.2). In nonaccommodation states, respondents were asked to continue organ support after declaration of DNC a mean of 6.1 times (SD 7.7). There was no difference between number of times this situation was encountered by respondents from accommodation states and nonaccommodation states. Details on respondents' experience with requests for provision of organ support after declaration of DNC are reported in table 3 .

Resources. In the event of a hypothetical situation in which a family requested continuation of organ support after DNC, about half of respondents (53\%) strongly or somewhat agreed that their institution would provide them with adequate resources to handle the situation, while $28 \%$ strongly or somewhat disagreed. There was no difference between responses from accommodation and nonaccommodation states. However, when asked about specific resources, more respondents in accommodation states indicated that they had access to an institutional DNC policy ( $81 \%$ vs $66 \%, p=0.018)$ and had an institutional ethics committee ( $88 \%$ vs $75 \%, p=0.022$ ) (see figure 2 for additional data on institutional resources). Respondents from all states indicated that their institutional policy allowed for accommodation to continue for varying lengths of time as follows: a compassionate period (29\%), until all family members are present $(24 \%)$, and until the hospital reaches a decision on how to proceed (20\%). More institutional policies in accommodation states than nonaccommodation states $(37 \%$ vs $21 \%, p=0.005)$ require accommodation after declaration of DNC for a compassionate period, which respondents specified as ranging from a few hours to a week (see
Economic issues. If a patient's family were to object to declaration of DNC on religious grounds in a state where accommodation is legally required, $50 \%$ of respondents believed that the primary source of funding for additional hospitalization should be the patient's insurance. Of the remaining respondents, 26\% 
Table 3 Respondents' experience with management of objection to discontinuation of organ support after death by neurologic criteria

\begin{tabular}{|c|c|c|c|}
\hline & $\begin{array}{l}\text { Accommodation } \\
\text { state respondents }\end{array}$ & $\begin{array}{l}\text { Nonaccommodation } \\
\text { state respondents }\end{array}$ & p Value \\
\hline $\begin{array}{l}\text { Reason physician believed family } \\
\text { requested continued organ support, a \% }\end{array}$ & $(n=39)$ & $(n=41)$ & \\
\hline Religious reason & 46 & 27 & 0.10 \\
\hline Moral objection & 28 & 10 & $0.039^{b}$ \\
\hline $\begin{array}{l}\text { The family saw acceptance of death } \\
\text { as giving up }\end{array}$ & 33 & 27 & 0.51 \\
\hline $\begin{array}{l}\text { Belief the patient could regain } \\
\text { neurologic function }\end{array}$ & 64 & 70 & 0.80 \\
\hline $\begin{array}{l}\text { Lack of acceptance that the patient } \\
\text { was dead because the patient's heart } \\
\text { was still beating }\end{array}$ & 59 & 39 & 0.12 \\
\hline $\begin{array}{l}\text { Desire to await arrival of additional } \\
\text { family members prior to } \\
\text { discontinuation of organ support }\end{array}$ & 85 & 73 & 0.38 \\
\hline $\begin{array}{l}\text { Desire to delay decision about organ } \\
\text { donation }\end{array}$ & 31 & 34 & 0.86 \\
\hline The patient was pregnant & 5 & 2 & 0.51 \\
\hline $\begin{array}{l}\text { The family wanted to continue } \\
\text { receiving social security benefits }\end{array}$ & 8 & 12 & 0.56 \\
\hline Other & 13 & 12 & 0.89 \\
\hline Unsure & 8 & 0 & 0.07 \\
\hline Physician response to request, \% & $(\mathrm{n}=39)$ & $(n=42)$ & 0.26 \\
\hline $\begin{array}{l}\text { Discontinuation of organ support } \\
\text { without family consent }\end{array}$ & 0 & 0 & \\
\hline $\begin{array}{l}\text { Discontinuation of organ support } \\
\text { with family consent }\end{array}$ & 44 & 33 & \\
\hline $\begin{array}{l}\text { Continuation of organ support for } \\
\text { a set amount of time }\end{array}$ & 31 & 45 & \\
\hline $\begin{array}{l}\text { Continuation of organ support } \\
\text { indefinitely }\end{array}$ & 10 & 2 & \\
\hline Other & 15 & 19 & \\
\hline $\begin{array}{l}\text { Reasons for discontinuation of organ } \\
\text { support, }{ }^{\text {a } \%}\end{array}$ & $(n=39)$ & $(n=42)$ & \\
\hline $\begin{array}{l}\text { Not applicable: the patient is still on } \\
\text { organ support at my institution }\end{array}$ & 3 & 0 & 0.30 \\
\hline $\begin{array}{l}\text { Not applicable: the patient was } \\
\text { transferred to a long-term care } \\
\text { facility or another hospital }\end{array}$ & 5 & 5 & 0.93 \\
\hline Cardiopulmonary death occurred & 31 & 41 & 0.46 \\
\hline A bed was needed & 0 & 2 & 0.34 \\
\hline $\begin{array}{l}\text { Fulfillment of the amount of time the } \\
\text { institutional protocol required } \\
\text { continuation of support }\end{array}$ & 15 & 10 & 0.43 \\
\hline $\begin{array}{l}\text { Fulfillment of the amount of time } \\
\text { ethics/legal/administration required } \\
\text { continuation of support }\end{array}$ & 21 & 24 & 0.77 \\
\hline $\begin{array}{l}\text { Fulfillment of the amount of time } \\
\text { agreed upon to continue support }\end{array}$ & 46 & 36 & 0.40 \\
\hline $\begin{array}{l}\text { The patient was pregnant, and the } \\
\text { baby was delivered }\end{array}$ & 3 & 0 & 0.30 \\
\hline $\begin{array}{l}\text { The patient was pregnant, and the } \\
\text { fetus died }\end{array}$ & 0 & 0 & - \\
\hline Other & 21 & 19 & 0.85 \\
\hline
\end{tabular}

${ }^{a}$ Respondents were permitted to select more than one response.

b Significant. table e-1 for additional data on institutional DNC policies).

Respondents offered a number of comments when asked, in an open-ended question, how the AAN could help make situations in which families object to DNC easier to handle. Comments were analyzed for theme. There were 43 requests for policy changes. Respondents asked for a policy with "clear, simple, universal guidelines" on what can/cannot and should/ should not be done in this situation, and for this policy to be supported by laws and shared with both physicians and the public. Many (30) respondents requested improvements in education on DNC targeting (1) the public, via publication in national magazines and newspapers and appearances on television by physicians, ethicists, and religious leaders addressing the meaning of DNC, particularly when cases such as Jahi McMath's ${ }^{14}$ are in the news; (2) families of patients being evaluated for DNC (multiple requests were made for creation of educational materials to disseminate during family meetings on this topic); and (3) physicians, both to improve understanding of DNC to prevent inaccurate determination and subsequent stories of survival/recovery after DNC and to keep them informed on best practices for management of these situations. Finally, 16 respondents requested the AAN advocate for codification of legislation on this topic to both guide and protect physicians throughout the country when they encounter these situations.

DISCUSSION We report the findings of a large-scale survey of neurologists addressing their beliefs on management of situations involving a family objecting to discontinuation of organ support after declaration of DNC and their personal experience with this type of situation. Our findings suggest that this situation is fairly common and is not restricted to states with accommodation exceptions ( $48 \%$ of respondents from accommodation states and $46 \%$ from nonaccommodation states indicated they encountered this situation) and that management of this situation varies by state, institution, and physician.

Inconsistent practice after DNC has also been reported outside of the United States. A prospective multicenter observational study in Spain found that organ support was continued in $18 \%$ of 553 patients who were declared DNC and were not donors. The authors inferred that health care professionals did not universally acknowledge DNC to be equivalent to death by cardiopulmonary criteria, but they did not note specific explanations for protracted organ support. ${ }^{15}$

In contrast, $93 \%$ of our respondents strongly or somewhat agreed that a person who is DNC is legally dead, suggesting that physician agreement with the 
Figure 2 The institutional resources to which respondents reported having access that could assist them in management if a family requests continuation of organ support after declaration of death by neurologic criteria

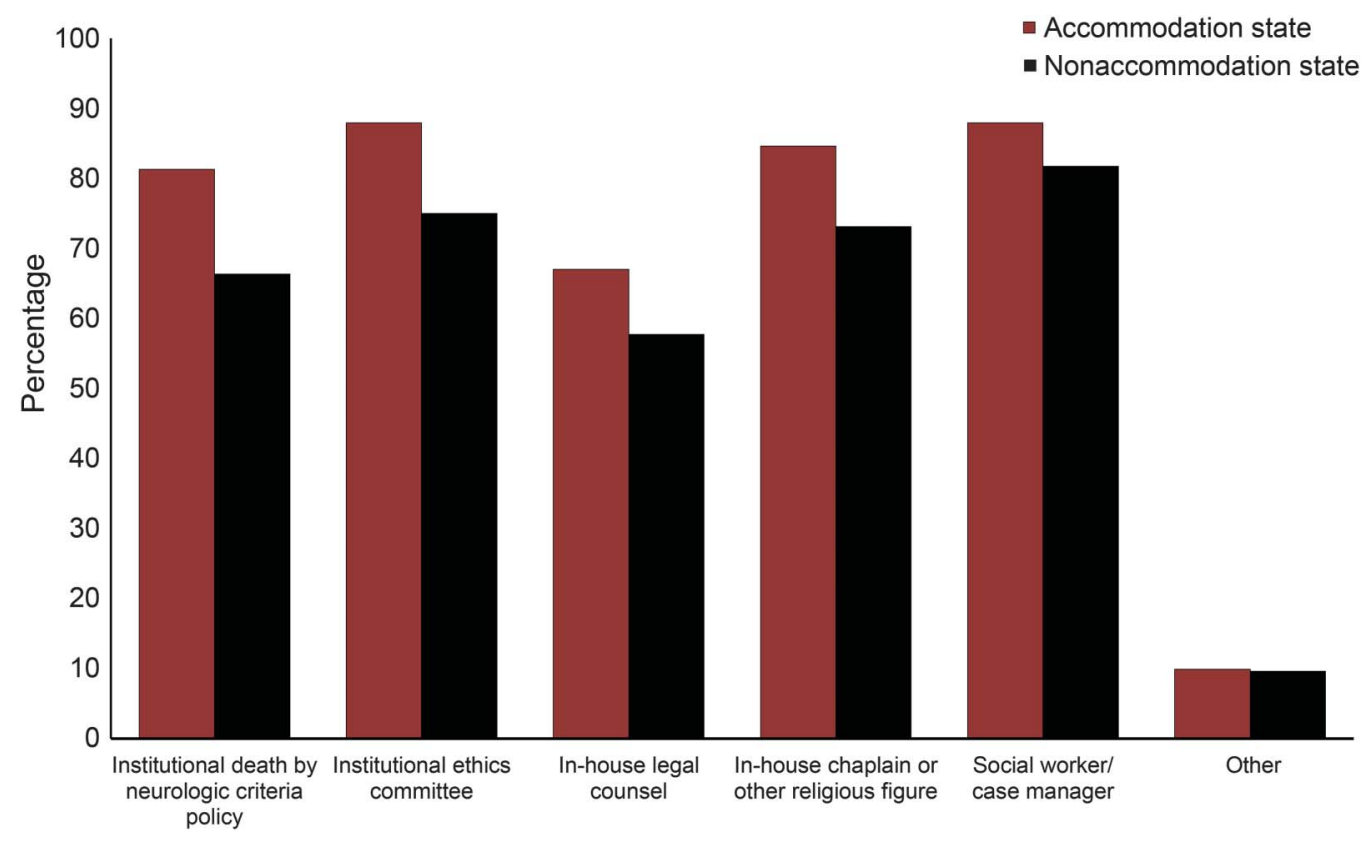

Ninety-one individuals from accommodation states and 104 individuals from nonaccommodation states responded to this survey question.

concept of DNC may not play a strong role in management of these situations in the United States. Respondents reported that their behavior in these situations was highly motivated by fear of litigation and media coverage, both of which have been reported to occur when families are dissatisfied. ${ }^{3,7,8,16}$

Many respondents requested the creation of guidelines for management of situations in which families object to discontinuation of organ support after DNC. Although delaying discontinuation of organ support can give a family time to come to terms with a patient's death, ${ }^{6,7,16}$ it can also promote confusion about the patient's status and increase the risk of complicated grief (a state of profound grief for greater than 6 months that is marked by disbelief, anger, bitterness, intrusive thoughts of the deceased, and difficulty moving on in life)..$^{3,5,6,8,17}$ For clinicians and hospital personnel, ongoing treatment after $\mathrm{DNC}$ can be seen as a violation of a patient's dignity and bodily integrity, and a misallocation of valuable resources including an intensive care unit bed, medical equipment, medications, and health care professionals' time and energy. ${ }^{3,5,6,8,9,16}$ These situations are emotionally taxing for both clinicians and families. ${ }^{3,8,18}$ Our findings suggest that guidelines for management of these situations should address the following controversial aspects of care after declaration of DNC: (1) the specific scenarios in which physicians should/can continue organ support; (2) the timeframe for continuation of organ support; (3) continuation and initiation of vasopressors, hormones, nutrition, and antibiotics; and (4) code status.

Respondents to our survey noted that improvements in public and clinician education about DNC are needed. It is well-known that in both the United States and abroad, public awareness of the irreversibility of DNC is poor. ${ }^{19}$ One would hope that medical students have a strong understanding of DNC, but a brief test showed that their level of understanding of this topic was low. ${ }^{20}$ These results were mirrored in a test on DNC given to practicing neurologists, who were able to correctly answer only $54 \%$ of questions. ${ }^{21}$ It is important for medical students to receive a solid education on this topic and for neurologists and other clinicians who are responsible for declaration of DNC to receive continuing education throughout their careers. Our findings suggest that this education should be focused on both the process of declaration of DNC and the ideal way to handle families who request continuation of organ support after DNC.

Finally, many respondents requested that the laws regarding declaration of DNC be identical in every state. This would require discussion of how to handle the multitude of reasons families object to discontinuation of organ support and whether or not religious and moral objection to DNC should be permissible. Notably, only $16 \%$ of respondents strongly or 
somewhat agreed that every state should allow for religious or moral objection to DNC. If moral objection to DNC were to be accepted throughout the United States as a reason to continue organ support after DNC, it would be necessary to clearly define moral objections. American culture places a high value on individualism, respect for autonomy, religious freedom, and privacy, ${ }^{5,16}$ but hospitals provide facilities for the living to receive necessary medical care, not for the dead to be maintained, ${ }^{6}$ and it is ethically precarious to allow a negotiated standard for determining death. ${ }^{8}$ Furthermore, equity dictates that patients who are DNC should be treated the same as patients who are dead by cardiopulmonary criteria. ${ }^{6}$

Practice surveys have limitations. Our results represent the opinion of respondents, but do not necessarily reflect the opinions of all members of the AAN. Our response rate was only $21 \%$, but this is on par with the response rates for all surveys distributed by the AAN in 2014 (minimum rate of $6 \%$, maximum rate of $30 \%$, mean of $16 \%$ ) and is a reflection of poor survey response rates among physicians due to time constraints, high survey burden, and lack of direct benefit to physicians who complete surveys. ${ }^{22}$ In addition, our study population only included neurologists, but at some institutions, other medical professionals such as neurosurgeons or registered nurses are also involved in declaration of DNC. ${ }^{23}$ Of note, it is possible that our survey was completed by multiple respondents from the same institution, because these data were not available during our participant selection process.

Protocols on discontinuation of organ support after declaration of DNC are known to vary. ${ }^{14}$ Our survey included questions on details about institutional protocols, but it is important to note that replies could be inaccurate if respondents did not review their institutional protocols while completing the survey.

Our findings suggest that it is relatively common for neurologists who treat critically ill patients to encounter families who object to discontinuation of organ support after DNC at some point during their careers. Physician and public education on this topic is warranted. Because management of this situation varies, it would be beneficial for physicians, families, and society to rely on clear medicolegal guidelines.

\section{AUTHOR CONTRIBUTIONS}

Ariane Lewis was responsible for conception and design, analysis and interpretation of data, drafting the manuscript, statistical analysis, and final approval of the manuscript. Nellie Adams was responsible for design, distribution, analysis and interpretation of data, statistical analysis, critical revision of the manuscript, and final approval of the manuscript. Panayiotis Varelas was responsible for design, critical revision of the manuscript, and final approval of the manuscript. David Greer was responsible for design, critical revision of the manuscript, and final approval of the manuscript. Arthur Caplan was responsible for conception and design, supervision, critical revision of the manuscript, and final approval of the manuscript.

\section{ACKNOWLEDGMENT}

The authors thank the Critical Care and Emergency Neurology Section; Ethics, Law, and Humanities Committee; and Member Research Subcommittee of the American Academy of Neurology for their assistance in reviewing the survey.

\section{STUDY FUNDING}

The survey was paid for by the American Academy of Neurology. As an employee of the American Academy of Neurology, Nellie Adams received funding from the Academy for her participation in this study. No other authors received financial compensation for this study.

\section{DISCLOSURE}

A. Lewis: This study was conceived and designed by Ariane Lewis, who is a member of the American Academy of Neurology, but does not serve on any committees or receive any funding from the Academy and does not have any conflicts of interest. The survey in this study was reviewed by the Critical Care and Emergency Neurology Section; Ethics, Law, and Humanities Committee; and Member Research Subcommittee of the American Academy of Neurology and distributed by the American Academy of Neurology. N. Adams is employed by the American Academy of Neurology. P. Varelas is a member of the advisory board of Gift of Life in Michigan and is a current member of the Vascular Section of the American Academy of Neurology and is the former Chair and a current member of the Critical Care and Emergency Neurology Section of the American Academy of Neurology. D. Greer is a member of the Critical Care and Emergency Neurology and Vascular Sections of the American Academy of Neurology and is the editor-in-chief of Seminars in Neurology. A. Caplan writes a regular column on medical ethics for nbc.com and is a regular commentator on WGBH BOSTON. Go to Neurology.org for full disclosures.

Received January 16, 2016. Accepted in final form May 11, 2016.

\section{REFERENCES}

1. Burkle CM, Schipper AM, Wijdicks EF. Brain death and the courts. Neurology 2011;76:837-841

2. Wijdicks EF. Determining brain death in adults. Neurology 1995;45:1003-1011.

3. Flamm AL, Smith ML, Mayer PA. Family members' requests to extend physiologic support after declaration of brain death: a case series analysis and proposed guidelines for clinical management. J Clin Ethics 2014;25:222-237.

4. Bosek MS. Respecting a patient's religious values: what does this require? JONAS Healthc L Ethics Regul 2008; 10:100-105.

5. Liao S, Ito S. Brain death: ethical challenges to palliative care concepts of family care. J Pain Symptom Manage 2010;40:309-313.

6. Burck R, Anderson-Shaw L, Sheldon M, Egan EA. The clinical response to brain death: a policy proposal. JONAS Healthc L Ethics Regul 2006;8:53-59.

7. Spike J, Greenlaw J. Ethics consultation: persistent brain death and religion: must a person believe in death to die? J Law Med Ethics 1995;23:291-294.

8. Smith ML, Flamm AL. Accommodating religious beliefs in the ICU: a narrative account of a disputed death. Narrat Inq Bioeth 2011;1:55-64.

9. Olick RS, Braun EA, Potash J. Accommodating religious, moral objections to neurological death. J Clin Ethics 2009; 20:183-191.

10. AB 2565 Assembly Bill. 2008. Available at: http://www. leginfo.ca.gov/pub/07-08/bill/asm/ab_2551-2600/ab_2565_ bill_20080927_chaptered.html. Accessed March 23, 2016. 
11. New Jersey Brain Death Statute. 2014. Available at: http:// www.njsharingnetwork.org/file/Brain-Death-GuidelinesJuly-27-2014sq-2.pdf. Accessed March 23, 2016.

12. New York State Guidelines for Determining Brain Death. 2011. Available at: http://www.health.ny.gov/professionals/ hospital_administrator/letters/2011/brain_death_guidelines. htm. Accessed March 23, 2016.

13. Illinois Compiled Statutes 210 ILCS 85 Hospital Licensing Act. Section 6.24-Illinois Attorney Resources: Illinois Laws. 2008. Available at: http://law.onecle.com/illinois/ 210ilcs85/6.24.html. Accessed August 13, 2015.

14. Lewis A, Varelas P, Greer D. Prolonging support after brain death: when families ask for more. Neurocrit Care 2016;24:481-486.

15. Escudero D, Valentín MO, Escalante JL, et al. Intensive care practices in brain death diagnosis and organ donation. Anaesthesia 2015;70:1130-1139.

16. Burt RA. The medical futility debate: patient choice, physician obligation, and end-of-life care. J Palliat Med 2002; 5:249-254.
17. Kentish-Barnes N, Chaize M, Seegers V, et al. Complicated grief after death of a relative in the intensive care unit. Eur Respir J 2015;45:1341-1352.

18. Curtis JR, Burt RA. Futility in the intensive care unit: hard cases make bad law. Crit Care Med 2010;38:1742-1743.

19. Shah SK, Kasper K, Miller FG. A narrative review of the empirical evidence on public attitudes on brain death and vital organ transplantation: the need for better data to inform policy. J Med Ethics 2015;41:291-296.

20. Tawil I, Gonzales SM, Marinaro J, Timm TC, Kalishman S, Crandall CS. Do medical students understand brain death? A survey study. J Surg Educ 2012;69:320-325.

21. MacDougall BJ, Robinson JD, Kappus L, Sudikoff SN, Greer DM. Simulation-based training in brain death determination. Neurocrit Care 2014;21:383-391.

22. Cunningham CT, Quan H, Hemmelgarn B, et al. Exploring physician specialist response rates to web-based surveys. BMC Med Res Methodol 2015;15:32.

23. Ghoshal S, Greer DM. Why is diagnosing brain death so confusing? Curr Opin Crit Care 2015;21:107-112. 


\section{Neurology}

\section{Organ support after death by neurologic criteria: Results of a survey of US neurologists}

Ariane Lewis, Nellie Adams, Panayiotis Varelas, et al.

Neurology 2016;87;827-834 Published Online before print July 22, 2016

DOI 10.1212/WNL.0000000000003008

This information is current as of July 22, 2016

\begin{tabular}{|c|c|}
\hline $\begin{array}{l}\text { Updated Information \& } \\
\text { Services }\end{array}$ & $\begin{array}{l}\text { including high resolution figures, can be found at: } \\
\text { http://n.neurology.org/content/87/8/827.full }\end{array}$ \\
\hline Supplementary Material & $\begin{array}{l}\text { Supplementary material can be found at: } \\
\text { http://n.neurology.org/content/suppl/2016/07/23/WNL.0000000000003 } \\
\text { 008.DC1 }\end{array}$ \\
\hline References & $\begin{array}{l}\text { This article cites } 19 \text { articles, } 4 \text { of which you can access for free at: } \\
\text { http://n.neurology.org/content/87/8/827.full\#ref-list-1 }\end{array}$ \\
\hline Citations & $\begin{array}{l}\text { This article has been cited by } 5 \text { HighWire-hosted articles: } \\
\text { http://n.neurology.org/content/87/8/827.full\#\#otherarticles }\end{array}$ \\
\hline Subspecialty Collections & $\begin{array}{l}\text { This article, along with others on similar topics, appears in the } \\
\text { following collection(s): } \\
\text { All Ethics in Neurology/Legal issues } \\
\text { http://n.neurology.org/cgi/collection/all_ethics_in_neurology_legal_iss } \\
\text { ues } \\
\text { Brain death } \\
\text { http://n.neurology.org/cgi/collection/brain_death }\end{array}$ \\
\hline Permissions \& Licensing & $\begin{array}{l}\text { Information about reproducing this article in parts (figures,tables) or in } \\
\text { its entirety can be found online at: } \\
\text { http://www.neurology.org/about/about_the_journal\#permissions }\end{array}$ \\
\hline Reprints & $\begin{array}{l}\text { Information about ordering reprints can be found online: } \\
\text { http://n.neurology.org/subscribers/advertise }\end{array}$ \\
\hline
\end{tabular}

Neurology ${ }^{\circledR}$ is the official journal of the American Academy of Neurology. Published continuously since 1951, it is now a weekly with 48 issues per year. Copyright (C 2016 American Academy of Neurology. All rights reserved. Print ISSN: 0028-3878. Online ISSN: 1526-632X.

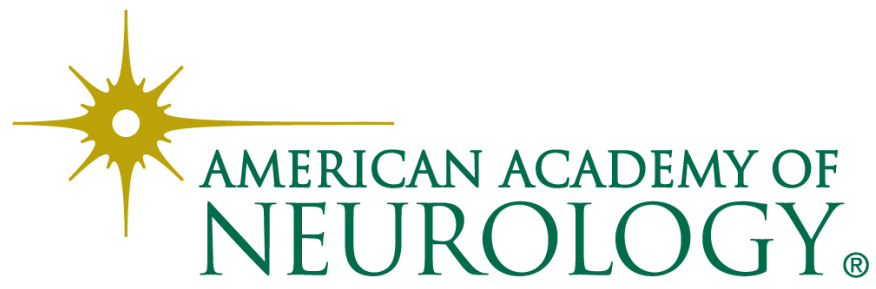

